\title{
Health locus of control and the sense of self-efficacy in patients with systolic heart failure: a pilot study
}

This article was published in the following Dove Press journal:

Patient Preference and Adherence

18 April 2013

Number of times this article has been viewed

\author{
Agnieszka Rydlewska ${ }^{1,2}$ \\ Justyna Krzysztofik ${ }^{3}$ \\ Julia Libergal ${ }^{3}$ \\ Agata Rybak ${ }^{3}$ \\ Waldemar Banasiak' \\ Piotr Ponikowski ${ }^{1,2}$ \\ Ewa A Jankowska ${ }^{1,2}$ \\ 'Centre for Heart Diseases, \\ Department of Cardiology, \\ Military Hospital, Wroclaw, Poland; \\ ${ }^{2}$ Department of Heart Diseases, \\ Wroclaw Medical University, \\ Wroclaw Poland; ${ }^{3}$ Student's Scientific \\ Organization, Laboratory for Applied \\ Research on Cardiovascular System, \\ Wroclaw Medical University, Wroclaw, \\ Poland
}

Correspondence: Agnieszka Rydlewska Department of Heart Diseases, Wroclaw Medical University, Weigla 5, 53-114 Wroclaw, Poland Tel +48 7I 7660275

Fax +48 7I 7660250

Email agnieszka.rydlewska@am.wroc.pl
Background: Treatment of heart failure (HF) requires the lifelong adherence to medical self-care regimes. The objective of this study was to examine health-control beliefs and the sense of self-efficacy (psychological features particularly important for efficient compliance among patients suffering from chronic diseases) in patients with systolic HF in relation to clinical status and depressive symptoms.

Subjects and methods: Sixty-six consecutive patients with chronic systolic HF, hospitalized in the Centre for Heart Diseases, Military Hospital (94\% men, age: $61 \pm 11$ years, ischemic etiology: $63 \%$, left ventricular ejection fraction: $32 \% \pm 12 \%$ ), filled in (during their hospital stay): (1) the Multidimensional Health Locus of Control Scale measuring three possible localizations of health control: "internality" (ie, the belief that health status depends only on personal decisions and behaviors); "powerful others externality" ([PHLC subscale] ie, the conviction that health depends on "powerful people" such as doctors, family members, close friends), and "chance externality" (ie, belief that health status is determined by chance, fate, or luck), and (2) the Generalized Self-Efficacy Scale. The results obtained by HF patients were compared to those reported by patients with other chronic diseases and healthy subjects.

Results: In patients with HF, internality was similar to values obtained by patients with diabetes, men after myocardial infarction, and women after mastectomy; and was lower than in healthy subjects. Powerful others externality was more pronounced in patients with HF as compared to other groups of patients and healthy people. Only women after mastectomy had higher scores of PHLC. In patients with HF, chance externality was similar to values reported in patients with renal failure, men after myocardial infarction, and women after mastectomy; and was less pronounced than in healthy subjects. The majority $(77 \%)$ of patients with HF were characterized by a high sense of self-efficacy ( $>$ the 7 th sten score), having the highest sense of self-efficacy among patients with other chronic diseases and healthy controls. Higher internality was accompanied by higher sense of self-efficacy $(P<0.05)$ in patients with HF. Subjects with high plasma N-terminal pro-B type natriuretic peptide (reflecting the disease severity) had the least pronounced internality $(P<0.05)$, whereas those with more advance depressive symptoms had the lower sense of self-efficacy $(P=<0.05)$.

Conclusion: Patients with systolic HF demonstrate a conviction that other people, including physicians, have a large influence on their health status, and at the same time are aware of the efficacy of their own activities in coping with the disease. Such a configuration of psychological features seems to be beneficial in the context of the developing modern strategies, which due to the improved cooperation between the physicians and the patients could enhance the compliance in patients with HF.

Keywords: health locus of control, self-efficacy, heart failure, compliance, depressive symptoms 


\section{Introduction}

Heart failure (HF) is a chronic, long-lasting condition, the progression of which can be partially postponed, but not stopped. ${ }^{1}$ The treatment strategy in HF requires the lifelong adherence to medical self-care regimes, such as: medications, dietary sodium restrictions, and self-monitoring (eg, daily weight measurements). ${ }^{1}$ Although high compliance improves outcomes in HF, in everyday clinical practice it is difficult to obtain and maintain high compliance in a long-term perspective. ${ }^{2}$

The reasons for noncompliance have not been clearly established; however, there are premises arising from the studies performed in patients with other chronic diseases that noncompliance may be related to the psychological features of patients ${ }^{3-5}$ and there are suggestions that psychological interventions could improve compliance among HF patients. ${ }^{2}$ In this context, two psychological features seem to be of crucial importance: ie, health locus of control and the sense of self-efficacy. ${ }^{3-5}$

Health locus of control refers to the individual's beliefs regarding the control of health, whereas the sense of self-efficacy reflects the individual's belief in his/her own skills to plan and perform certain activities to attain particular aims. ${ }^{6}$ None of these features have been investigated in patients with HF. Thus, the objective of this study was to examine the health control beliefs and the sense of self-efficacy in patients with stable systolic HF, also in the context of their clinical status and depressive symptoms.

\section{Subjects and methods Study population}

We examined patients with systolic HF hospitalized in the Centre for Heart Diseases, Military Hospital (Wroclaw, Poland). There were the following inclusion criteria for the study: (1) a >6-month documented history of HF (New York Heart Association [NYHA] I-III classes); ${ }^{1}$ (2) clinical stability with unchanged medications for $\geq 3$ months preceding the study; and (3) left ventricular ejection fraction $<45 \%$ as assessed by echocardiography.

Exclusion criteria comprised: (1) HF decompensation within 3 months preceding the study; (2) acute coronary syndrome and/or coronary revascularization during the 6 months preceding the study; and (3) any psychiatric abnormalities and associated therapy either at the time of examination or in the past.

The study was approved by the local ethics committee. All subjects gave written informed consent. The study was conducted in accordance with the Declaration of Helsinki.

\section{Study protocol}

Each patient underwent a physical examination with routine laboratory tests and standard transthoracic echocardiography. Plasma N-terminal pro-B type natriuretic peptide ([NT-proBNP] pg/mL) was measured using electrochemiluminescence on the Elecsys 1010/2010 System (Roche Diagnostics GmbH, Mannheim, Germany). Renal function was assessed using the estimated glomerular filtration rate ([GFR] $\mathrm{mL} /$ minute $/ 1.73 \mathrm{~m}^{2}$ ), calculated from the Modification of Diet in Renal Disease equation. ${ }^{7}$ Serum high-sensitive C-reactive protein (hsCRP, $\mathrm{mg} / \mathrm{L}$ ) was assessed using immunonephelometry (analyser no BN II, Dade Behring, Siemens AG, Munich, Germany). Afterwards, each patient completed psychological questionnaires assessing.

1. the health locus of control, and

2. the sense of self-efficacy.

Health locus of control (ie, the set of personal beliefs regarding the control of individual health status), was assessed using the Polish version of the Multidimensional Health Locus of Control Scale ([MHLC] forms A and B), originally proposed by Wallston et $\mathrm{al}^{8}$ and adopted by Juczynski in 1999. ${ }^{9}$ MHLC measures three possible localizations of health control: internal localization, called "internality" (internal locus of control, measured by a subscale named IHLC) and two external localizations called "powerful others externality" (measured by a subscale named PHLC) and "chance externality" (measured by a subscale named CHLC). ${ }^{8,9}$

Patients with high internality (those having high scores on the IHLC subscale) believe that their health status depends only on their own behaviors.

Patients with high powerful others externality (expressed as high scores on the PHLC subscale) are convinced that their individual health status is the consequence of the actions performed by powerful people, eg, doctors, family members, friends.

Patients with high chance externality (expressed as high scores on the CHLC subscale) believe that mainly chance, fate, or luck determine their health status. ${ }^{8,9}$

Each subscale is composed of six items. The answers for each item are expressed using a 6-point Likert scale, where the lowest score (1) means "strongly disagree," and the highest score (6) means "strongly agree;", ",9 thus, it is possible to obtain from 6 to 36 points in each subscale. The initial publication regarding these scales established the fact that they are internally consistent and concurrently valid. Patients with HF examined in the present study were compared with 
patients with other chronic diseases and healthy subjects (based on values from the instructions for the MHLC). ${ }^{8,9}$

The sense of self-efficacy was measured using the Polish version of the Generalized Self-Efficacy Scale (GSES) originally developed by Schwarzer and Jerusalm, ${ }^{10}$ and also adopted by Juczynski. ${ }^{9}$ GSES measures how an individual judges his/her own competence in order to complete tasks (by the means of behaviors, thoughts, and emotions) and reach desired goals. GSES includes ten items, each answered with a 4-point Likert type scale, where 1 means "not at all true" and 4 means "exactly true". Validity and internal consistency of a Polish version has been confirmed in a group of 496 healthy adults. ${ }^{9}$ Normalization enables us to transform the results of the GSES to sten scores. A sten score indicates an individual's approximate position in the context of the values characteristic for the normal, general population. ${ }^{17}$ Sten scores range from 1 to 10 . GSES scores assigned to $1-3,4-6$, and 7-10 sten scores are interpreted as the low, moderate, and high sense of self-efficacy, respectively. ${ }^{9}$

Afterwards, each patient completed the Beck Depression Inventory ([BDI] version Ia) ${ }^{11}$ for assessing depressive symptoms. The BDI is a self-administered, 21-item self-report inventory, with the possibility to differentiate depressive symptoms as cognitive-affective (the first 13 items of the BDI) and somatic (the remaining items), using the Polish version of the BDI. The BDI score $\leq 10$ points indicated no depressive symptoms, whereas the BDI score $\geq 16$ suggested the presence of at least mild depressive symptoms. ${ }^{12}$

\section{Statistical analyses}

Normally distributed continuous variables were presented as means \pm standard deviations. The intergroup differences were tested using Student's $t$-test. Variables with a skewed distribution were expressed as medians with lower and upper quartiles, and were log transformed in order to normalize their distributions. The categorical variables were expressed as numbers with percentages. The inter-group differences were tested using the $\chi^{2}$ test. Relationships between the analyzed variables were assessed using Pearson's correlatory coefficients (for normally distributed continuous variables) or Spearman's rank correlatory coefficients (for variables with a skewed distribution or categorical variables).

A value of $P<0.05$ was considered statistically significant.

\section{Results}

Sixty-six patients with systolic HF were enrolled in the study. The majority of them were males, classified in the NYHA I-II classes, and received standard pharmacotherapy (Table 1). A BDI score $\geq 16$ was recorded in approximately $40 \%$ of the examined subjects.

\section{Health locus of control and the sense of self-efficacy in patients with HF}

The distribution of MHLC scores recorded in patients with HF was presented in Table 2. The most pronounced localization of health control in examined patients with HF were powerful others externality and internality. Low, moderate, and high

Table I Baseline characteristics of 66 examined patients with systolic heart failure

\begin{tabular}{|c|c|}
\hline Variables & Patients with HF $(n=66)$ \\
\hline Age (years) & $61 \pm 11$ \\
\hline Men (n [\%]) & 60 (91\%) \\
\hline BMI $\left(\mathrm{kg} / \mathrm{m}^{2}\right)$ & $28.5 \pm 4.1$ \\
\hline Ischemic HF etiology (n [\%]) & $63(95 \%)$ \\
\hline NYHA classes I/II/III (n [\%]) & II (I7\%)/39 (59\%)/16 (24\%) \\
\hline LVEF (\%) & $32 \pm 12$ \\
\hline NT-proBNP (pg/mL) & $|25|(59 \mid-3923)$ \\
\hline Hypertension (n [\%]) & 31 (47\%) \\
\hline $\mathrm{DM}(\mathrm{n}[\%])$ & $23(35 \%)$ \\
\hline Hemoglobin (g/dL) & $18.8 \pm 1.7$ \\
\hline eGFR-MDRD (mL/minute/l.73 m²) & $71.2 \pm 22.7$ \\
\hline Sodium (mmol/L) & $140 \pm 3$ \\
\hline hsCRP (mg/L) & $3.34(1.50-9.23)$ \\
\hline BDI score & $13 \pm 9$ \\
\hline BDI-scores: $\leq|0 / 1|-|5 / \geq| 6(n[\%])$ & $25(38 \%) / / 3(20 \%) / 28(42 \%)$ \\
\hline BDI score for C-A & $6 \pm 6$ \\
\hline BDI score for $\mathrm{S}$ & $8 \pm 4$ \\
\hline \multicolumn{2}{|l|}{ Treatment } \\
\hline ACEI and/or ARB (n [\%]) & $50(75 \%)$ \\
\hline Beta-blocker (n [\%]) & $57(86 \%)$ \\
\hline Aldosterone antagonist (n [\%]) & $34(51 \%)$ \\
\hline Digoxin (n [\%]) & $12(18 \%)$ \\
\hline Loop diuretic (n [\%]) & $25(38 \%)$ \\
\hline Thiazide diuretic (n [\%]) & $21(32 \%)$ \\
\hline Statin (n [\%]) & $48(73 \%)$ \\
\hline ASA (n [\%]) & $35(52 \%)$ \\
\hline
\end{tabular}

Note: Results are presented as a mean \pm standard deviation, a median with lower and upper quartiles, or a number with a percentage.

Abbreviations: ACEl, angiotensin converting enzyme inhibitor; ARB, angiotensin receptor antagonist; ASA, acetylsalicylic acid; BDI, Beck Depression Inventory; BMI, body mass index; (C-A), BDI subscale for cognitive and affective depressive symptoms; DM, diabetes mellitus; eGFR-MDRD, estimated glomerular filtration rate calculated using the MDRD formula; $\mathrm{HF}$, heart failure; hsCRP, high sensitivity C-reactive protein; LVEF, left ventricular ejection fraction; MDRD, Modification of Diet in Renal Disease; NT-proBNP, N-terminal pro-B type natriuretic peptide; NYHA, New York Heart Association; S, BDI subscale for somatic symptoms of depression. 


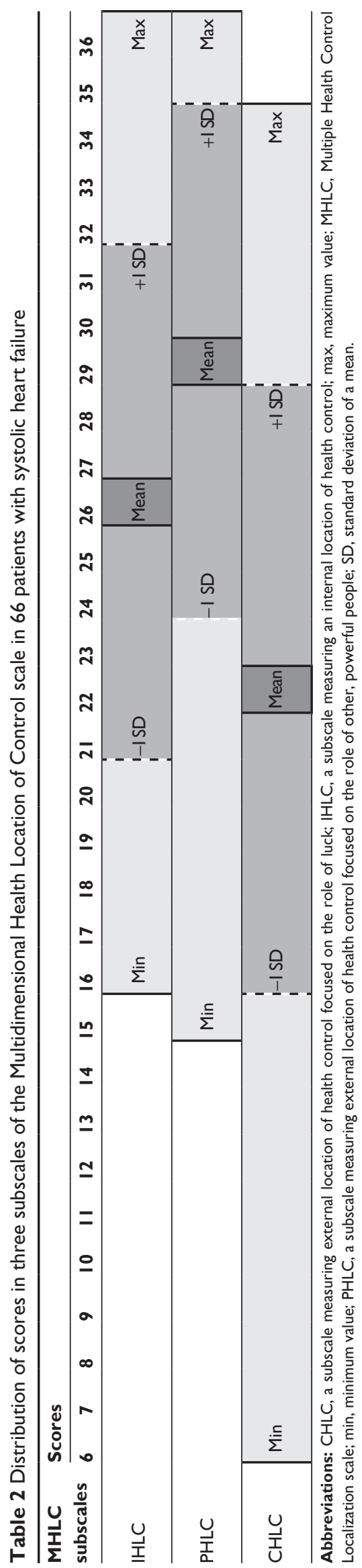

sense of self-efficacy was found in $2 \%, 14 \%$, and $77 \%$ of patients with HF, respectively.

\section{Health locus of control and the sense of self-efficacy in patients with HF compared with patients with other chronic diseases and healthy subjects}

Internality was similar in patients with HF, patients with diabetes, men after myocardial infarction, and women after mastectomy (all $P>0.2$ ), and was lower as compared to healthy subjects $(P<0.05)$ (Table 3$)$.

Powerful others externality was more pronounced in patients with $\mathrm{HF}$ as compared to patients with other chronic diseases and healthy people (all $P<0.05$ ), in spite of women after mastectomy, who had higher PHLC scores $(P<0.05)$ (Table 3).

Chance externality was similar in patients with chronic diseases, including those with HF, renal failure, men after myocardial infarction, and women after mastectomy (all $P>0.2$ ). In patients with HF, chance externality was less pronounced than among healthy subjects $(P<0.05)$ (Table 3 ).

Patients with HF had the highest sense of self-efficacy as compared to the other groups of patients with chronic diseases and healthy controls. Patients with systolic HF with the higher sense of self-efficacy had also more pronounced internality $(\mathrm{r}=0.29, P=0.02)$.

\section{Associations between health control and self-efficacy, and clinical status of patients with HF}

The magnitude of internality was inversely related to plasma NT-proBNP in patients with HF $(\mathrm{r}=-0.43, P=0.03)$. There were no other relationships between health control localization, the sense of self-efficacy, and any clinical variable (all $P>0.2$ ).

\section{Associations between health control and self-efficacy, and depressive symptoms of patients with HF}

Patients with systolic HF with higher sense of self-efficacy were characterized by less pronounced depressive symptoms ( $\mathrm{r}=-0.26, P=0.04)$, both affective-cognitive $(\mathrm{r}=0.32$, $P=0.01)$ and somatic depressive symptoms $(\mathrm{r}=-0.28$, $P=0.03)$.

\section{Discussion}

As far as we are aware, this is the first report providing evidence on the localization of health control and the sense 
Table 3 Mean values of MHLC and GSES scores in patients with systolic heart failure, patients with other chronic diseases, and healthy subjects

\begin{tabular}{|c|c|c|c|c|c|c|c|}
\hline \multirow[t]{2}{*}{ Variables } & \multirow{2}{*}{$\begin{array}{l}\text { Patients with HF } \\
n=66\end{array}$} & \multicolumn{4}{|c|}{ Patients with other chronic diseases 9} & \multicolumn{2}{|l|}{ Healthy subjects ${ }^{9}$} \\
\hline & & $\begin{array}{l}\text { Patients with DM } \\
\mathrm{n}=\mathbf{7 0}\end{array}$ & $\begin{array}{l}\text { Patients with } \\
\text { renal failure } \\
n=3 \text { I }\end{array}$ & $\begin{array}{l}\text { Men after } M I \\
n=42\end{array}$ & $\begin{array}{l}\text { Women after } \\
\text { mastectomy } \\
n=30\end{array}$ & $\begin{array}{l}\text { Healthy men and } \\
\text { women living in a } \\
\text { big city } \\
n=264\end{array}$ & $\begin{array}{l}\text { Healthy men } \\
\text { and women } \\
n=496\end{array}$ \\
\hline $\begin{array}{l}\text { IHLC } \\
\text { (points) }\end{array}$ & $26 \pm 5$ & $26 \pm 6$ & $24 \pm 3^{*}$ & $26 \pm 4$ & $25 \pm 5$ & $28 \pm 5^{*}$ & - \\
\hline $\begin{array}{l}\text { PHLC } \\
\text { (points) }\end{array}$ & $29 \pm 5$ & $26 \pm 7^{*}$ & $25 \pm 4^{*}$ & $25 \pm 5^{*}$ & $31 \pm 5^{*}$ & $20 \pm 6^{*}$ & - \\
\hline $\begin{array}{l}\mathrm{CHLC} \\
\text { (points) }\end{array}$ & $22 \pm 6$ & $20 \pm 7^{*}$ & $22 \pm 5$ & $22 \pm 6$ & $22 \pm 6$ & $18 \pm 6^{*}$ & - \\
\hline $\begin{array}{l}\text { GSES } \\
\text { (points) }\end{array}$ & $32 \pm 4$ & $28 \pm 5^{*}$ & $27 \pm 5^{*}$ & $27 \pm 6^{*}$ & $30 \pm 4^{*}$ & - & $27 \pm 5^{*}$ \\
\hline
\end{tabular}

Notes: Results are presented as mean \pm standard deviations. $* P<0.05-$ the particular group versus patients with systolic HF.

Abbreviatons: CHLC, a subscale measuring external location of health control focused on the role of luck; DM, diabetes mellitus; GSES, Generalized Self-Efficacy Scale; HF, heart failure; IHLC, a subscale measuring an internal location of health control; MHLC, Multiple Health Control Localization scale; MI, myocardial infarction; PHLC, a subscale measuring external location of health control focused on the role of other, powerful people.

of self-efficacy in patients with stable systolic HF living in contemporary Poland. Both features seem to be important in the context of the HF management and the level of self-care among these patients. There are only a few studies focused on the localization of health control and the sense of selfefficacy in patients with stable systolic HF in the international literature. $^{12-15}$

The localization of health control is important in the context of coping with chronic diseases. Internality and powerful others externality are positively related to drug compliance in patients with schizophrenia, ${ }^{15}$ internality predicts better adherence to treatment recommendations among patients with chronic pain, ${ }^{16}$ as well as among injured athletes. ${ }^{17}$ High self-efficacy is related to self-care behaviors in kidney transplant recipients, ${ }^{7}$ in patients with diabetes, ${ }^{18}$ and also in healthy people. ${ }^{19}$

It seems that patients with HF are unique with regard to these two psychological features as compared to the other groups of patients with chronic diseases living in Poland. The most pronounced localization of health control in examined patients with HF was powerful others externality, which may suggest that they could potentially seriously take into consideration medical advice from physicians. The magnitude of internality was relatively high, indicating that they could also take substantial responsibility for their health status. Most importantly, patients with HF were characterized by much higher sense of self-efficacy as compared to the other groups of patients. ${ }^{9}$ Both features should be taken into consideration while planning modern strategies aiming to improve self-care and compliance in patients with HF.

In the present study, we found no associations between the health-control localization, the sense of self-efficacy, and clinical parameters, in spite of the inverse relationship between plasma NT-proBNP (a parameter which reflects the severity of the disease; higher NT-proBNP is characteristic of more advanced HF) and internality. This may be related to the common awareness in contemporary societies that the most important causes of cardiovascular diseases (eg, HF) are the consequence of unhealthy lifestyles, ${ }^{20}$ which is related to the common conscience of the individual responsibility for one's health status.

Depressive symptoms are common in patients with HF, and are related to the severity of the disease..$^{12}$ In the present study, the higher sense of self-efficacy was accompanied by less marked depressive symptoms in patients with HF, which is consistent with previous studies in patients with chronic diseases ${ }^{18,21}$ as well as among healthy people..$^{22}$ Importantly, the sense of self-efficacy can be a mediator in the reaction to strong stressors (eg, chronic disease and related debilitating symptoms, such as dyspnea in HF) and the occurrence of depressive symptoms. ${ }^{23}$ It has been demonstrated that the increase in self-efficacy due to a modeling intervention in patients with HF was followed by a significant improvement in clinical status (eg, a reduction of exercise intolerance expressed by an increased peak oxygen consumption). ${ }^{24}$

\section{Limitations}

We are aware that our study has some limitations related to the applied methodology, which need to be acknowledged.

Firstly, our results may be affected by selection bias, as there is no doubt that there are differences in psychological features between those who agree and disagree to participate in this kind of study, and we will never be able to familiarize 
ourselves with the psychological features of subjects who refuse to fill in psychological questionnaires. Moreover, the study was performed among hospitalized patients. It is likely that the results obtained among outpatient clinic patients with HF, who were not included in the present study, would be different. As a result, our findings cannot be generalized beyond the studied group.

Secondly, all applied questionnaires are typical selfreported measures, which are related with a potential risk of misstatement.

Thirdly, the present study constitutes a preliminary report regarding two psychological features that may be related to self-care and compliance with medical regimes in patients with HF. We did not analyze an actual rate of compliance among examined patients, and undoubtedly such analyses should be performed as the continuation of our project.

\section{Conclusion}

Patients with systolic HF demonstrate a conviction that other people, including physicians, have a large influence on their health status, and at the same time are aware of the efficacy of their own activities in coping with the disease. Such a configuration of psychological features seems to be beneficial in the context of the developing modern strategies, which (due to the improved cooperation between the physicians and the patients) could enhance compliance in patients with HF.

\section{Acknowledgments}

The project was funded by The National Science Centre, Cracow, Poland, grant number 2011/03/N/NZ5/00243, and by Wroclaw Medical University, Wroclaw, Poland (statutory activities of Laboratory for Applied Research on Cardiovascular System in 2012, ST-722).

\section{Disclosure}

The authors report no conflicts of interest in this work.

\section{References}

1. McMurray JJ, Adamopoulos S, Anker SD, et al; Task Force for the Diagnosis and Treatment of Acute and Chronic Heart Failure 2012 of the European Society of Cardiology; ESC Committee for Practice Guidelines. ESC Guidelines for the diagnosis and treatment of acute and chronic heart failure 2012: The Task Force for the Diagnosis and Treatment of Acute and Chronic Heart Failure 2012 of the European Society of Cardiology. Developed in collaboration with the Heart Failure Association (HFA) of the ESC. Eur J Heart Fail. 2012;14(8):803-869.

2. van der Wal MH, Jaarsma T, van Veldhuisen DJ. Non-compliance in patients with heart failure; how can we manage it? Eur J Heart Fail. 2005;7(1):5-17.

3. Burkhart PV, Rayens MK. Self-concept and health locus of control: factors related to children's adherence to recommended asthma regimen. Pediatr Nurs. 2005;31(5):404-409.
4. Keedy NH. Health Locus of Control, Self-efficacy, and Multidisciplinary Intervention for Chronic Back Pain [dissertation]. Iowa City: University of Iowa; 2009.

5. Weng LC, Dai YT, Huang HL, Chiang YJ. Self-efficacy, self-care behaviours and quality of life of kidney transplant recipients. $J A d v$ Nurs. 2010;66(4):828-838.

6. Tabassum U, Rehman G. The relationship between self-efficacy and depression in physically handicapped children. Journal of Pakistan Psychiatry Society. 2005;2(1):37.

7. Levey AS, Bosch JP, Lewis JB, et al. A more accurate method to estimate glomerular filtration rate from serum creatinine: a new prediction equation. Modification of Diet in Renal Disease Study Group. Annals of Internal Medicine. 1999;130(6):461-470.

8. Wallston K, Stein MJ, Smith CA. Form C of the MHLC Scale: a condition-specific measure of locus of control. J Pers Assess. 1994; 63(3):534-553.

9. Juczynski Z. Narzedzia pomiaru w promocji i psychologii zdrowia [Measurement tools in the promotion and health psychology]. Pracownia Testów Psychologicznych Polskiego Towarzystwa Psychologicznego. 2001. 79-84, 93-97. Polish.

10. Schwarzer R and Jerusalem M. Measurement of perceived self-efficacy: Psychometric scales for cross-cultural research. Berlin: Freie Universität Berlin, Institut for psychologie; 1993.

11. Beck AT, Ward CH, Mendelson M, Mock J, Erbaugh J. An inventory for measuring depression. Arch Gen Psychiatry. 1961;4: 561-571.

12. Jankowska EA, Drohomirecka A, Ponikowska B, et al. Deficiencies in circulating testosterone and dehydroepiandrosterone sulphate, and depression in men with systolic chronic heart failure. Eur J Heart Fail. 2010;12(9):966-973.

13. Maeda U, Shen BJ, Schwarz ER, Farrell KA, Mallon S. Self-efficacy mediates the associations of social support and depression with treatment adherence in heart failure patients. Int $J$ Behav Med. Epub January 3, 2012.

14. Park CL, Sacco SJ, Edmondson D. Expanding coping goodness-of-fit: religious coping, health locus of control, and depressed affect in heart failure patients. Anxiety Stress Coping. 2012;25(2):137-153.

15. Combes C, Feral F. Drug compliance and health locus of control in schizophrenia. Encephale. 2011;37 Suppl 1:S11-S18. French.

16. Kurita GP, Pimenta CA. Compliance with the treatment of chronic pain and health control locus. Rev Esc Enferm USP. 2004;38(3):254-261. Portuguese.

17. Murphy GC, Foreman PE, Simpson CA, Molloy GN, Molloy EK. The development of a locus of control measure predictive of injured athletes' adherence to treatment. J Sci Med Sport. 1999;2(2): $145-152$.

18. Cherrington A, Wallston KA, Rothman RL. Exploring the relationship between diabetes self-efficacy, depressive symptoms, and glycemic control among men and women with type 2 diabetes. J Behav Med. 2010;33(1):81-89.

19. Pedersen MM, Zebis MK, Langberg H, et al. Influence of self-efficacy on compliance to workplace exercise. Int J Behav Med. Epub May 24, 2012.

20. Volpe M, Pignatelli G, Paneni F. Polytherapy in cardiovascular prevention: open issues. G Ital Cardiol (Rome). 2012;13(7-8):503-510. Italian.

21. Weber BA, Roberts BL, Resnick M, et al. The effect of dyadic intervention on self-efficacy, social support, and depression for men with prostate cancer. Psychooncology. 2004;13(1):47-60.

22. Holahan CK, Holahan CJ. Self-efficacy, social support, and depression in aging: a longitudinal analysis. J Gerontol. 1987;42(1):65-68.

23. Maciejewski PK, Prigerson HG, Mazure CM. Self-efficacy as a mediator between stressful life events and depressive symptoms. Differences based on history of prior depression. Br J Psychiatry. 2000;176: 373-378.

24. Maddison R, Prapavessis H, Armstrong GP, Hill C. A modeling intervention in heart failure. Ann Behav Med. 2008;36(1):64-69. 
Patient Preference and Adherence

Dovepress

\section{Publish your work in this journal}

Patient Preference and Adherence is an international, peer-reviewed, open access journal focusing on the growing importance of patient preference and adherence throughout the therapeutic continuum. Patien satisfaction, acceptability, quality of life, compliance, persistence and their role in developing new therapeutic modalities and compounds to optimize clinical outcomes for existing disease states are major areas of interest. This journal has been accepted for indexing on PubMed Central. The manuscript management system is completely online and includes a very quick and fair peer-review system. Visit http://www.dovepress.com/ testimonials.php to read real quotes from published authors.

Submit your manuscript here: http://www.dovepress.com/patient-preference-and-adherence-journal 